\title{
Gothic Writing Technique and Yin-Yang Theory in The Fall of the House of Usher"
}

\author{
Bing Han \\ School of Foreign Language, Jining Medical University, Rizhao, China \\ Mo Guo \\ School of Foreign Language, Jining Medical University, Rizhao, China
}

\begin{abstract}
In both theoretical and practical senses, Gothic writing techniques and Yin-Yang theory share many similarities. To some extent, Gothic writing techniques can be explained by Yin-Yang theory and their application in Gothic fictions can be transferred to corresponding regulations in Yin-Yang theory. This paper mainly looks into the similarities and dissimilarities of them, specifically in Edgar Allen Poe's The Fall of the House of Usher. This paper studies this two terms from a philosophical perspective.
\end{abstract}

Index Terms - Gothic writing technique, Chinese Yin-Yang, philosophical perspective

\section{Gothic Writing TeChNique IN THE FALl OF THE HOUSE OF USHER}

\section{A. A General Introduction of Gothic Writing Technique}

Gothic writing technique is a writing method widely used in Gothic fictions, mainly referring to the adoption of words and expressions related to death and darkness to create a sense of horror. To fully understand Gothic writing technique, we need to take a look at the origin and development of Gothic fictions. Gothic fictions originated from British novelist Horace Walpole who first applied it in his novel The Castle of Otranto, which is also titled A Gothic Story in its second edition. Gothic fictions are a genre or mode of literature that combines fiction, horror and Romanticism, and sometimes is referred to as Gothic horror. The influence of Gothic novels depends on a delightful kind of horror, an expansion of Romantic literary joys that were relatively new at the age of Walpole's fiction. Other long-lasting characteristics initiated by Walpole in Gothic fictions including melodrama and parody. It can be dated back to England in the latter part of the 18th century and had much success in the 19th as can be seen through Mary Shelley's Frankenstein and the works of Edgar Allan Poe. Bram Stoker's Dracula is another world-known example in this genre, which dated to the end of Victorian age. The word "Gothic" refers to those buildings constructed in the Medieval, in which many of Gothic stories were set. This ultimate form of romanticism was very prevalent in Germany as well as Britain.

Representatively, the fundamental characters of Gothic novel include an innocent virtuous kind pure beautiful young woman, a hero, a scoundrel, a foolish footman, jokers, and a clergy hierophant, etc. The setup of the Gothic fiction is also a significant character itself. The stories usually happened in a castle, a monastery, an abbey, or some other, primarily religious mansion, and it is conceived that this building has hidden facts in it, be it related with the people living in there or the things happened in there. From the beginning of one Gothic fiction, the audience should be anticipating the depressing and horrifying scenery and get ready to be immersed in it. A London review of the Castle of Otranto made the significance of setting in Gothic fictions quite manifest. "He describes the country towards Otranto as desolate and bare, extensive downs covered with thyme, with occasionally the dwarf holly, and lavender, stretch around like wild moorlands"(Wikipedia September 29th). The mournful Castle of Otranto was described by Mr. Williams as "an imposing object of considerable size...has a dignified and chivalric air. A fitter scene for his romance he probably could not have chosen"(Wikipedia September 29th). Likely, De Vore said, "The setting is greatly influential in Gothic novels. It not only evokes the atmosphere of horror and dread, but also portrays the deterioration of its world. The decaying, ruined scenery implies that at one time there was a thriving world. At one time the abbey, castle, or landscape was something treasured and appreciated. Now, all that lasts is the decaying shell of a once thriving dwelling"(Wikipedia September 29th). Therefore, the Gothic fiction would not exist if the pre-set background depiction were eliminated.

In modern literature, the concept of Gothic fictions has been enormously widened; some scholars view it as natural revealment of female's fear towards uneven society, while others prefer to regard it as the release of the authors' twisted

\footnotetext{
${ }^{*}$ This paper is part of the result of Planning and Research Project of Social Science granted by Social Science Planning and Management Office of Shandong Province (19CWZJ10): Studies on the Cultivation of Chinese EFL Learners 'Intercultural Critical Thinking Ability. It is also supported by Planning and Research Project of Social Science (16CWZJ14), Supporting Funds for Teachers' Scientific Research by Jining Medical University (JYFC2018RW005), Education and Science Research Project by Jining Medical University (18008) and Industry-University Collaborative Education Project by Ministry of Education (201801245013).
} 
sexual desire. But no matter what kind of view, they have one thing in common, and that is in text type, they believe it is an open system across time and space and national borders. In their viewpoints, Gothic fictions are not a settled literary genre in history, but rather an ordinary horror fiction form. This fiction form has lasted till now, not only including the universally acknowledged classics, but also including the ghost stories and horror fictions, even some horror sexual fictions. American scholar Fredrick Frank made his review in Guide to the Gothic III: An Annotated Bibliography of Criticism, "Perhaps the best direction in the study of the Gothic novel in the new century is to looking for a blend between the traditional view and radical view" (Wikipedia September 29th). The term "Gothic" is inseparably connected with the history, and it is also a history of words. Meanwhile it is a prefab, self regenerative term, which can be used to represent a series of situations and acceptance. In order to critics and the general reader to keep vitality, the term "Gothic novel" is best understood as both having the literary tradition of space and time, and transcending the limitation of time and space. These remarks probably could be considered as the most proper comments on modern Gothic fictions.

\section{B. Application of Gothic Writing Technique in the Novel}

In The Fall of the House of Usher, Poe applied Gothic writing technique in characterization, environment setting and plot designing.

Firstly, Poe made himself as an observer of the story, to be more specific, a survivor. His description of the master of the house of Usher, namely Roderick Usher, occupied a prominent position at the beginning of the novel. In his words, Roderick "gave evidence of nervous agitation"; "his reserve has always excessive and habitual"(Poe, 2005, p. 4). And after the author entered the house of Usher, he made an even more vivid description of Roderick, not only covered his appearance but also his vocal features.

"Yet the character of his face had been at all times remarkable. A cadaverousness of complexion; an eye large, liquid, and luminous beyond comparison; lips somewhat thin and very pallid, but of a surprisingly beautiful curve; a nose of a delicate Hebrew model, but with a breadth of nostril unusual n similar formations; a finely-molded chin, speaking, in its want of prominence, of a want of moral energy; hair of a more than web-like softness and tenuity; these features, with an inordinate expansion above the regions of the temple, made up altogether a countenance not easily to be forgotten", (Poe, 2005, p. 7). "His voice varied rapidly from a tremulous indecision to that species of energetic concision" (Poe, 2005, p. 11). These words depicted the master of house of Usher as a bizarre and weird character with very obvious Gothic features. While reading these lines, readers can not help themselves but feel the irresistible coldness from the character, which is an important feature of Gothic writing technique. Besides Roderick, another main character even more significant in the novel is Roderick's sister Lady Madeline. Her appearance is initially attached with death, because Poe's first words about her are "...to the severe and long-continued illness indeed to the evidently approaching dissolution of a tenderly beloved sister..." (Poe, 2005, p. 17) and at the night of the narrator's arrival at the house, she passed away even before the author got a chance to meet her. However the shadow of her death never faded away in the novel, until her final reappearance in the climax of the novel. Continual evidences found either by her brother or the narrator claimed that this young lady had never really rested in peace. And the most amazing part is, regardless of all the evidences, the readers are never sure about her death, and her reappearance in the end satisfies readers' desire for horror and more. This is just a tip of the iceberg that reveals how excellently Poe applied Gothic writing technique.

Secondly, Gothic writing technique usually arranges the story in medieval buildings and The Fall of the House of Usher is no exception. At the beginning of the novel, Poe made detailed descriptions about the house of Usher and the surroundings. "Its principal feature seemed to be that of an excessive antiquity"(Poe, 2005, p. 2). He repeatedly used these words "dull" "dark" "soundless" "melancholy" "a sense of insufferable gloom" (Poe, 2005, p. 1) to render the environment around the house and then he depicted the inside of the house as "an air of stern, deep, and irredeemable gloom hung over and pervaded all" (Poe, 2005, p. 1). The whole tone of the novel has been settled by these descriptions and just by the first few pages, Poe successfully made his readers feel the house is a place of darkness and death.

Thirdly, in plot designing, the most distinguishable Gothic writing technique with Poe's personal touch is symbolism. For instance, "...a barely perceptible fissure, which, extending from the roof of the building in front, made its way down the wall in a zigzag direction, until it became lost in the sullen waters of the tarn" (Poe, 2005, p. 8). “...the fissure rapidly widened - there came a fierce breath of the whirlwind - the entire orb of the satellite burst at once upon my sight..."(Poe, 2005, p. 21). Throughout the novel, this kind of symbolism is everywhere, which gives hints of the depressing development of the story. All the symbols Poe used in the novel have one thing in common-they were all descending, deteriorating, and rotting, just like the house itself and finally they all collapsed and disappeared into the black and lurid tarn in front of the house of Usher.

\section{YIN-YANG THeORY IN THE FALL OF THE HousE OF USHER}

\section{A. A Gist of Yin-Yang Theory}

Yin-Yang is an ancient concept of Chinese philosophy used to demonstrate how opposite or contrary elements are interdependent or interconnected in the natural world and how they influence each other in their interrelationship. Many natural dualities are thought to be the physical manifestations of Yin Yang concept, for instance: male and female, day and night, hot and cold, life and death. The concept exists in the origins of many branches of Chinese 
classical science and philosophy, as well as being a primary guideline of traditional Chinese medicine and a central principle of different forms of Chinese martial arts and exercises, such as baguazhang, t'ai chi, qigong and I Ching (Wikipedia September, $29^{\text {th }}$ ).

Yin and yang can be thought of as complementary forces interacting to form a dynamic system in which the whole is greater than the parts. Everything has both yin and yang aspects, for instance shadow cannot exist without light. Either of the two major aspects may manifest more strongly in a particular object, depending on the criterion of the observation (Wikipedia September, $29^{\text {th }}$ ).

The relationship between Yin and Yang is often described in terms of sunlight playing over a mountain and a valley. Yin (literally the "shady place" or "north slope") is the dark area occluded by the mountain's bulk, while yang (literally the "sunny place" or "south slope") is the brightly lit portion. As the sun moves across the sky, yin and yang gradually trade places with each other, revealing what was obscured and obscuring what was revealed.

Yin is characterized as slow, soft, yielding, diffuse, cold, wet, and passive; and is associated with water, earth, the moon, femininity and nighttime (Wikipedia September, $29^{\text {th }}$ ).

Yang, by contrast, is fast, hard, solid, focused, hot, dry, and aggressive; and is associated with fire, sky, the sun, masculinity and daytime (Wikipedia September, $29^{\text {th }}$ ).

Originally, Yin-Yang theory was applied in Chinese traditional medicine. Yin and yang applies to the human body. In traditional Chinese medicine good health is directly related to the balance between yin and yang qualities within oneself. If yin and yang become unbalanced, one of the qualities is considered deficient or has vacuity. However, the concept of Yin-Yang has been widened gradually and applied in construction, religion and other aspects.

\section{B. Analysis of the Novel in Perspective of Yin-Yang Theory}

At the beginning of the novel, Poe repeatedly used "dull, dark, and soundless" "melancholy" "a sense of insufferable gloom" "iciness, a sinking, a sickening" "a black and lurid tarn" (Poe, 2005, p. 1) to emphasize the Yin elements around the house of Usher, and in this way, rendering the horrifying environment. Then the description of the inside decoration of house of Usher and its master further shed light upon the Yin feature of the house itself and the people living in it. From the novel we can tell that the principal feature of the house seemed to be that of an excessive antiquity, and the master of the house was morbid and mentally-disordered. Both of them were full of Yin characteristics, and that is how Poe set a depressing and irredeemable tone for the entire novel. Some specific depiction of Roderick, as his facial feature, is the vivid manifestation of Yin features, for instance: "the ghastly pallor of the skin, the miraculous luster of the eye" (Poe, 2005, p. 7). Yet, one character with the most distinguishable Yin feature should be Roderick's sister, lady Madeline who first came to the view of the readers as "indeed to the evidently approaching dissolution of a tenderly beloved sister" (Poe, 2005, p. 9) and not after long was taken by death and settled in the vault (although she was probably not dead). Both of the two characters were bothered by sickness be it mentally or physically. From the perspective of Yin-Yang theory, this means they were overwhelmed by Yin factors and thus they probably would end up with death. Then Poe used a series of hints to suggest that the climax is approaching, and no one could resist the aggressive sense of horror. These hints include a disturbing poem titled "The Haunted Palace", the low and apparently distant, but harsh sound, etc. Finally the climax came with the sentence "we have put her living in the tomb" (Poe, 2005, p. 18)! and thus reveals the reappearance of Lady Madeline in front of the door. The rest of the novel just took up two paragraphs, but contains the climax and ending of the novel, Lady Madeline eventually dead as falling on her brother, which also caused the death of Roderick. Till now, the Yin factor has taken over the entire house. Death, thunder storm outside the window, uneven night, all these Yin factors contribute to the sense of horror in readers' minds. From the development of the novel we can tell that Poe applies increasingly obvious Yin elements to add horror to the novel, and reaches the peak with the ultimate Yin finale, the eternal death.

A specific Gothic writing technique that Poe applied in his novel stands out above others, and that is symbolism. It also corresponds to the Yin-Yang theory. A remarkable instance can demonstrate the point. There is a black and lurid tarn in front of the house of Usher when the author first saw it "with a shudder even more thrilling than before" (Poe, 2005 , p. 3) in his words. From these descriptions we can get that the lurid serves as the core of Yin factor, and the following development of the novel confirms our inference. "...the still waters of the tarn. Its evidence-the evidence of the sentience - was to be seen, he said, in the gradual yet certain condensation of an atmosphere of their own about the waters and the walls." (Poe, 2005, p. 12) Here we can say, the gathering atmosphere around the lake is Yin elements, and the accumulation of that indicates the upcoming horror. Finally, the ending of the novel specifically pointed out that the tarn is the core of Yin factors. "...my brain reeled as I saw the mighty walls rushing asunder-there was a long tumultuous shouting sound like the voice of a thousand waters - and the deep and dank tarn at my feet closed sullenly and silently over the fragments of the "House of Usher" (Poe, 2005, p. 21). All the death and horror ended up in the sullen and silent tarn, therefore indicated that the Yin factors aggregated into one object. The Yin factor took over everything and left the remaining sense of horror in the readers' mind.

\section{Similarities AND Dissimilarities BETWEen Gothic Writing TECHNIQUE AND Yin-YANG ThEORY}

\section{A. Similarities in Theoretical Sense}

The similarities of Gothic writing technique and Yin-Yang theory mainly concentrated on the involvement of 
negative elements. With Gothic writing technique authors applied in their novels, negative elements as horrible death or haunted castle are used to render the environment, and in this way, set up a vivid imaginary dimension for the readers. In Yin-Yang theory, ancient Chinese people divided the whole world into Yin and Yang, and the Yin side of the world consists of things practically identical to the symbols in Gothic writing techniques. So from this perspective, Gothic writing techniques and Yin-Yang theory have the similar essentials in theoretical sense.

\section{B. Similarities in Practical Sense}

In terms of applicability, we can see that Gothic writing techniques are used in literature works, and as stated before, we can also use Yin-Yang theory to analyze Gothic fictions. So they both can be applied in the critic of literature works. In general, Gothic writing techniques are applied by the authors through expanding the Yin elements and surpassing the Yang elements to build the sense of depression, gloom and horror.

In Poe's The Fall of the House of Usher, this similarity is quite apparent. The surroundings around the house of Usher are filled with Yin elements, which set the fundamental tone for the entire novel. And one significant symbol in the novel, the black and lurid tarn, is set as the core of Yin in the novel. With the development of the story, its power gathers and accumulates, we can tell this trend from this part: "Its evidence- the evidence of the sentience-was to be seen, he said, "In the gradual yet certain condensation of an atmosphere of their own about the waters and the walls" (Poe, 2005, p. 2). In the end, the Yin core became the destination of everything, and finally crushed the remaining Yang factors, "...the deep and dank tarn at my feet closed sullenly and silently over the fragments of House of Usher" (Poe, 2005, p. 21). Another notable Gothic figure is the very House of Usher itself. "Its principal feature seemed to be that of an excessive antiquity" (Poe, 2005, p. 2). From this sentence, the readers immediately get the feeling that Yin is one of the most obvious features of the House of Usher. And yet another one thing adds to the degree of Yin attribute is "a barely perceptible fissure, which extending from the roof of the building in front, made its way down the wall in a zigzag direction, until it became lost in the sullen waters of the tarn" (Poe, 2005, p. 4). This one feature combines one Yin factor with the core of Yin around the house and thus became the fishing touch of the entire novel.

Hence, we can say that Gothic writing techniques can be explained by Yin-Yang theory and their application in Gothic fictions can be transferred to corresponding regulations in Yin-Yang theory. In both theoretical and practical senses, Gothic writing techniques and Yin-Yang theory share many similarities.

\section{Dissimilarities between Gothic Writing Technique and Yin-Yang Theory}

The similarities between Gothic writing techniques and Yin-Yang theory have been covered in the previous chapters. Therefore in this chapter, we would focus on the dissimilarities.

For starters, their definition and origin are widely divergent. Gothic writing techniques were originated in 18th century Britain as a literature style, and then popularized by authors in Europe. When it arrived in American, Poe became the first novelist who created the Gothic writing technique with American feature in it. In its later development, it experienced a period of ignorance; literary critics equaled Gothic fictions to erotic works. However, in current literary world, a bunch of talented writers made great achievements with Gothic fictions, and the concept of Gothic has been enormously widened. Nowadays, basically all fictions with horror factors can be classified as Gothic fictions. Besides literature creation, it is also extensively applied in literary critic.

On the other hand, Yin-Yang theory was an ancient philosophical concept concluded by Chinese sagas. It conceives many principles of philosophy that inherited by generations of Chinese people. At the beginning it was applied in traditional Chinese medicine. Chinese doctors healed people through adjusting the balance between Yin and Yang in human body. This theory contains a very significant principle of Chinese philosophy, which is harmony. To keep harmony, human beings need to adjust the balance between Yin and Yang, thus they can maintain a steady state and avoid catastrophe. In the later centuries, this concept has been expounding to other fields such as architecture and religious belief. The most distinguished development of Yin-Yang theory probably is Taoism; it further divided the world into five basic elements, which are fire, wood, water, gold, soil. All these factors impact and suppress each other and finally return to harmony.

Therefore, we can tell the major differences between Gothic writing techniques and Yin-Yang theory. The former is a writing style and a critic method in literature, the latter is a philosophical concept and covers a larger range in the universe.

\section{CONCLUSION}

Edgar Ellen Poe (1809-1849), American novelist and poet, was recognized in much of the world as the pioneer in Gothic fictions. Hundreds of editions of his Gothic fictions have been published. Scholars have written thousands of books and articles about his plots, characters, themes, and language. He is so well known in the world and many of his fictions has been adopted to films and presented on the big screens.

His miraculous way to stir the horror and darkness inside human hearts left millions of people a deep impression. View his unique Gothic writing technique from a philosophical perspective makes the readers have a clearer understanding towards his writing clue, and thus makes his fiction even more interesting. 
It is also inspiring to know that there is a possibility to analyze a literature work with a foreign ancient philosophy concept, which offers one more choice when it comes to literature comment.

\section{REFERENCES}

[1] Gothic fiction. Wikipedia Search Tool. http://wikipedia.moesalih.com/Gothic_fiction (accessed 29/9/2019).

[2] Pan, Ziqiang. (2006). The Fall of the House of Usher (Translation Version). Guangzhou: Guangdong Publishing Group Flower City Publishing House.

[3] Poe, Edgar Allen. (1839). The Fall of the House of Usher. United States: Burton's Gentleman's Magazine.

[4] Poe, Edgar Allen. (2005). The Fall of the House of Usher $1^{\text {st }}$ edition, Beijing: Liberation Army Art Press.

[5] Yin-Yang. Wikipedia Search Tool. http://wikipedia.moesalih.com/Yin_Yang (accessed 29/9/2019).

Bing Han was born in Jining, China in 1983. She received her master degree in TEFL from University of Birmingham, UK in 2008.

She is currently a lecturer in the School of Foreign Languages, Jining Medical University, Rizhao, China. Her research intere sts include pedagogy and intercultural communication.

Mo Guo, born on July 11th 1992, he graduated from McGill University in Canada, with a master degree in Second language Education. His research field is language assessment. 